\title{
ASSESSMENT OF THE FREQUENCY OF DIFFERENT PATTERNS OF CLINICAL PRESENTATION OF CHILDREN PRESENTING WITH CONGENITAL ADRENAL HYPERPLASIA.
}

\author{
HABIB ULLAH ${ }^{1}$, FAYIZA MANZOOR AHMAD ${ }^{1}$, SUMAIRA HAMID ${ }^{2}$, NOOR UL AIN MEHAK ${ }^{3}$, \\ ASSIYA AFZAL ${ }^{4}$, SAQIB MUNIR ${ }^{2}$ \\ ${ }^{1}$ Department of Pediatrics, The Children's hospital and Institute of child health, Lahore, ${ }^{2}$ Mayo Hospital \\ Lahore, ${ }^{3}$ Services hospital, Lahore, ${ }^{4}$ Civil hospital, Bahawalpur
}

\begin{abstract}
Objective: To assess the frequency of different patterns of presentation of children presenting with congenital adrenal hyperplasia.

Methods: It was a cross sectional study conducted at the department of Pediatric, Fatima Memorial Hospital, Lahore, from19-12-2017 to 19-06-2018.92 infants who met the selectin criteria were recruited for the study. Then blood sample was obtained and if serum sodium $<135 \mathrm{mEq} / \mathrm{L}$, then salt depletion was labeled. Then, infants underwent genital examination for assessment of genital virilization. All data is entered is specially designed Performa and analyzed in SPSS. Results: The mean age of patients was $6.52 \pm 3.56$ months. There were $49(53.26 \%)$ male while $43(46.74 \%)$ female infants. The mean weight of patients was $5.59 \pm 1.44 \mathrm{~kg}$. There were $21(22.83 \%)$ cases of consanguineous marriage while 71 (77.17\%) were other than cousin marriage. There were $63(68.48 \%)$ had salt depletion while in $29(31.52 \%)$ did not had salt depletion. There were 39 (42.39\%) had genital virilization while in $53(57.61 \%)$ did not had genital virilization.

Conclusion: Thus the frequency of patterns (salt depletion and genital virilization) of congenital adrenal hyperplasia are high in local population.
\end{abstract}

Key words: Patterns, salt depletion, genital virilization, congenital adrenal hyperplasia, infants, consanguineous marriage

How to cite this article: Ullah H, Ahmad FM, Hamid S, Mehak NUA, Afzal A, Munir S. Assessment of the frequency of different patterns of clinical presentation of children presenting with congenital adrenal hyperplasia. Pak Postgrad Med J 2020;31(4): 178-181

This is an Open Access article distributed under the terms of the Creative Commons Attribution License (http://creativecommons.org/licenses/by/3.0), which permits unrestricted use, distribution, and reproduction in any medium, provided the original work is properly cited.

DOI: http://doi.org/10.51642/ppmj.v31i04.388

Correspondence to: Habib Ullah, Department of Pediatrics, The Children's hospital and Institute of child health, Lahore, Pakistan.

Email:Habib_ullah8@yahoo.com

\section{INTRODUCTION}

Congenital adrenal hyperplasia is the autosomal recessive disorder, which is described due to the defects in any of the five enzymes which are required for the production of cortisol. ${ }^{1}$ It disturbsabout1 in 18,000 live born neonates in the United Kingdom. Not all the cases of congenital adrenal hyperplasia diagnosed within first year of life. Screening of newborns for congenital adrenal hyperplasia is not in practice in the United Kingdom, however it is under debate by the National Screening Committee. ${ }^{2}$
In about $95 \%$ cases of congenital adrenal hyperplasia, deficiency of 21-hydroxylase enzyme has been observed, which leads to the reduction in the production of cortisol and aldosterone. ${ }^{3}$ This causes the deficiency in cortisol level, raises the adrenocorticotropic hormone, adrenal hyperplasia and also the high adrenal androgen secretions. There is significant virilization in genetic females which is the symbol of this disorder. ${ }^{4}$

Overproduction of the adrenal androgen leads to the prenatal and post-natal virilization. Phenotypes of the congenital adrenal hyperplasia differ with the extent of enzymes deficiency. Pre-natal virilization in female newborns and salt wasting in both genders, during neonatal time period can develop because of complete deficiency of enzymes. ${ }^{3}$ The classical phenotypes are salt-wasting and simple genital virilizing forms..$^{5,6}$ 
In a study, conducted on 82 cases it was showed that consanguinity rate was high $(71.2 \%), 95 \%$ had salt depletion and $52 \%$ had genital virilization. ${ }^{7}$ One more study conducted on 28 cases showed that $60.7 \%$ cases had salt depletion and $39.3 \%$ had genital virilization. ${ }^{8}$ But one study conducted on 58 cases showed that $0 \%$ cases had salt depletion while genital virilization was observed in $14 \%$ cases only. ${ }^{9}$

Rationale of this study is to assess the frequency of different patterns of presentation of children presenting with congenital adrenal hyperplasia. Literature has shown that congenital adrenal hyperplasia has high prevalence of salt depletion and genital virilization in infants but controversial evidence has also been noticed in literature. So we want to conduct this study to confirm whether these complications are high in local population as there is no local evidence obtained in literature regarding the pattern of presentation of congenital adrenal hyperplasia. So we have planned to conduct this study on large sample size to get more authentic results which will be applicable in local population.

\section{METHODS}

This Cross sectional study was done at the Department of Pediatric, Fatima Memorial Hospital, Lahore for about 6 months i.e. 19-12-2017 to 19-06-2018. Sample size (n) of 92 cases was estimated by using $95 \%$ confidence level, fixing margin of error at $10 \%$ and percentage of female genital virilization i.e. $39.9 \%$ in infants presenting with congenital adrenal hyperplasia. Infants were included by applying Non-Probability, Consecutive sampling as those were included who fulfilled selection criteria. Infants of age 1-12months of either gender presenting with congenital adrenal hyperplasia. It was defined as presence of raised plasma 17-hydroxyprogesterone $>1000 \mathrm{ng} / \mathrm{dl}$. Infants reported during the $1^{\text {st }}$ month of life with confirmed established disease, or infants with other congenital problems (chromosomal abnormality, neural tube defects, cerebral palsy) on clinical examination were excluded from the study. After taking the written consent form from the parents, the demographic information of infants (name, gender, age and weight) were also taken. Then the blood sample was taken by using the $3 \mathrm{cc}$ disposable syringe with the help of staff nurse under the aseptic measures. All the blood samples were stored and sent to the pathology laboratory for assessment of serum sodium level. If serum sodium $<135 \mathrm{mEq} / \mathrm{L}$ and dehydration (lethargy, tinting skin), then salt depletion was labeled. Then, infants underwent genital examination for assessment of genital virilization. In female infant if there was clitoral enlargement on clinical examination. In male infants of there was micropenis, underdeveloped scrotum and bilateral undescended testes. All data was entered in apre-designed Performa.
The data was analyzed by using the computer software named as SPSS v. 20. Numerical variables like age, and weight were calculated as mean and standard deviation. Categorical variables like gender and pattern of congenital adrenal hyperplasia (salt depletion and genital virilization) were presented in form of frequency (\%). Data was stratified for age, gender, weight of children and consanguineous marriage and stratified groups were compared for pattern by using chi-square test. $\mathrm{P} \leq 0.05$ was considered as significant.

\section{RESULTS}

The mean age of patients was $6.52 \pm 3.56$ months. There were $49(53.26 \%)$ male while $43(46.74 \%)$ female infants. The mean weight of patients was $5.59 \pm 1.44 \mathrm{~kg}$. There were $21(22.83 \%)$ cases of consanguineous marriage while $71(77.17 \%)$ were other than cousin marriage. Table 1

There were $63(68.48 \%)$ had salt depletion while in 29 $(31.52 \%)$ did not had salt depletion. There were 39 $(42.39 \%)$ had genital virilization while in $53(57.61 \%)$ did not had genital virilization. Table 2

Data was stratified for age of patients. In patients aged $\leq 6$ months, salt depletion was found in 31 (72.1\%) cases. In patients aged $>6$ months, salt depletion was found in 32 $(65.3 \%)$ cases. The difference was insignificant ( $\mathrm{p}$-value $>0.05$ ). Data was stratified for gender of patients. In male patients, salt depletion was found in 37 (75.5\%) cases. In female patients, salt depletion was found in $26(60.5 \%)$ cases. The difference was insignificant ( $\mathrm{p}$-value $>0.05$ ). Data was stratified for weight of patients. In patients weighed $3.0-5.5 \mathrm{~kg}$, salt depletion was found in 30 $(71.4 \%)$ cases. In patients weighed $5.6-8.0 \mathrm{~kg}$, salt depletion was found in $33(66.0 \%)$ cases. The difference was insignificant ( $p$-value $>0.05$ ). Data was stratified for consanguineous marriage. In patients with consanguineous marriage, salt depletion was found in 11 $(52.4 \%)$ cases. In patients without consanguineous marriage, salt depletion was found in $52(73.2 \%)$ cases. The difference was insignificant ( $\mathrm{p}$-value $>0.05$ ). Table 3

Data was stratified for age of patients. In patients aged $\leq 6$ months, genital virilization was found in 13 (30.2\%) cases. In patients aged $>6$ months, genital virilization was found in $26(53.1 \%)$ cases. The difference was significant $(\mathrm{p}<0.05)$. Data was stratified for gender of patients. In male patients, genital virilization was found in 17 $(34.7 \%)$ cases. In female patients, genital virilization was found in $22(51.2 \%)$ cases. The difference was insignificant ( $p$-value >0.05). Data was stratified for weight of patients. In patients weighed $3.0-5.5 \mathrm{~kg}$, genital virilization was found in $15(35.7 \%)$ cases. In patients weighed $5.6-8.0 \mathrm{~kg}$, genital virilization was found in 24 $(48.0 \%)$ cases. The difference was insignificant (p-value $>0.05)$. 
Table 1: Demographics of patients

\begin{tabular}{lc}
\hline $\mathrm{N}$ & 92 \\
Age (years) & $6.52 \pm 3.56$ \\
Gender & \\
$\quad$ Male & $49(53.26 \%)$ \\
Female & $43(46.74 \%)$ \\
Weight $(\mathrm{kg})$ & $5.59 \pm 1.44$ \\
Consanguinity & $21(22.83 \%)$ \\
\hline
\end{tabular}

Table 2: Clinical presentation of children with congenital adrenal hyperplasia

\begin{tabular}{lc}
\hline Total patients & 92 \\
Salt depletion & $63(68.5 \%)$ \\
Genital virilization & $39(42.4 \%)$ \\
\hline
\end{tabular}

Table 3: Comparison of salt depletion in different strata

\begin{tabular}{|c|c|c|c|c|c|}
\hline & \multicolumn{3}{|c|}{ Salt depletion } & \multirow[b]{2}{*}{$\begin{array}{c}\mathrm{p}^{-} \\
\text {value }\end{array}$} \\
\hline & & & $\begin{array}{l}\text { Yes } \\
n=63)\end{array}$ & $\begin{array}{c}\text { No } \\
(\mathrm{n}=29)\end{array}$ & \\
\hline \multirow{2}{*}{ Age (months) } & $\leq 6$ & & $72.10 \%$ & $1227.90 \%$ & \multirow{2}{*}{0.485} \\
\hline & $>6$ & & $65.30 \%$ & $1734.70 \%$ & \\
\hline \multirow{2}{*}{ Gender } & Male & 37 & $75.5 \%$ & $1224.5 \%$ & \multirow{2}{*}{0.121} \\
\hline & Female & 26 & $60.5 \%$ & $1739.5 \%$ & \\
\hline \multirow{2}{*}{ Weight (kg) } & $3.0-5.5$ & 30 & $71.4 \%$ & $1228.6 \%$ & \multirow{2}{*}{0.577} \\
\hline & $5.6-8.0$ & 33 & $66.0 \%$ & $1734.0 \%$ & \\
\hline \multirow{2}{*}{$\begin{array}{l}\text { Consanguineous } \\
\text { marriage }\end{array}$} & Yes & 11 & $52.4 \%$ & $1047.6 \%$ & \multirow{2}{*}{0.071} \\
\hline & No & 52 & $73.2 \%$ & $1926.8 \%$ & \\
\hline
\end{tabular}

Table 4: Comparison of genital virilization in different strata

\begin{tabular}{|c|c|c|c|c|c|}
\hline & \multicolumn{5}{|c|}{ Genital virilization } \\
\hline & & $\begin{array}{c}\text { Yes } \\
(n=39)\end{array}$ & & $\begin{array}{l}\text { No } \\
=53)\end{array}$ & $\begin{array}{c}\mathrm{p}^{-} \\
\text {value }\end{array}$ \\
\hline \multirow{2}{*}{ Age (months) } & $\leq 6$ & $1330.2 \%$ & 30 & $69.8 \%$ & \\
\hline & $>6$ & $2653.1 \%$ & 23 & $46.9 \%$ & 0.0 \\
\hline \multirow{2}{*}{ Gender } & Male & $1734.7 \%$ & 32 & $65.3 \%$ & \\
\hline & Female & $2251.2 \%$ & 21 & $48.8 \%$ & \\
\hline \multirow{2}{*}{ Weight (kg) } & $3.0-5.5$ & $1535.7 \%$ & 27 & 26 & \\
\hline & $5.6-8.0$ & $2448.0 \%$ & $54.3 \%$ & $52.0 \%$ & \\
\hline \multirow{2}{*}{$\begin{array}{c}\text { Consanguineous } \\
\text { marriage }\end{array}$} & Yes & $838.1 \%$ & 13 & $61.9 \%$ & \\
\hline & No & $3143.7 \%$ & 40 & $56.3 \%$ & \\
\hline
\end{tabular}

Data was stratified for consanguineous marriage. In patients with consanguineous marriage, genital virilization was found in $8(38.1 \%)$ cases. In patients without consanguineous marriage, genital virilization was found in $31(43.7 \%)$ cases. The difference was insignificant ( $\mathrm{p}$-value $>0.05)$. Table 4

\section{DISCUSSION}

Congenital adrenal hyperplasia is the autosomal recessive disorder. It occurs mostly due to the deficiency of 21-hydroxylase enzymes action, which usually decrease the level of cortisol and aldosterone secretions, though on the same time increases the production of androgens. ${ }^{10}$ Physical growth is thought to be the key concern for the treatment of the congenital adrenal hyperplasia, as in these cases, children do not achieve their target height as compared to normal children. Management of congenital adrenal hyperplasia depends on the administration of dose of glucocorticoids and mineralocorticoids, which reduce the adrenocorticotropic hormone -stimulated excess of the adrenal androgen. Maximized doses of the hydrocortisone can be given to obtain the satisfactory suppression of androgens, with succeeding hyper-cortisolism. ${ }^{11-12}$

In our study, there were $63(68.48 \%)$ had salt depletion while in $29(31.52 \%)$ did not had salt depletion. There were $39(42.39 \%)$ had genital virilization while in 53 $(57.61 \%)$ did not had genital virilization. In a study, conducted on 82 cases it was showed that consanguinity rate was high $(71.2 \%), 95 \%$ had salt depletion and $52 \%$ had genital virilization. These finding indicated the significance of the awareness of pediatricians and the requirement of the neonatal screening programme for early recognition and suitable treatment. ${ }^{7}$

One more study conducted on 28 cases showed that $60.7 \%$ cases had salt depletion and $39.3 \%$ had genital virilization. There are few factors like age at the time of diagnosis and at the initiation of therapy, the glucocorticoid dose, fludrocortisones dose or dose of saline therapy, which are not significantly associated with poor growth of infants diagnosed with salt wasting congenital adrenal hyperplasia. While other factors likemal gender and mean basal length below -2SD were significantly associated with more promising growth catch-up growth. Further prospective trials with the inclusion of comorbid conditions and nutritional status must be done. ${ }^{8}$

But one study conducted on 58 cases showed that $0 \%$ cases had salt depletion while genital virilization was observed in $14 \%$ cases only. Screening of the newborn proposes the probability to avert the serious clinical exhibitions in older children with undiagnosed congenital adrenal hyperplasia; but, it can also be detected in few children who usually remain asymptomatic and also in those the benefit from treatment is uncertain. ${ }^{9}$

The mean age of patients was $6.52 \pm 3.56$ months. Data was stratified for age of patients. In patients aged $\leq 6$ months, salt depletion was found in $31(72.1 \%)$ cases. In patients aged $>6$ months, salt depletion was found in 32 $(65.3 \%)$ cases. The difference was insignificant ( $p$-value $>0.05$ ). Data was stratified for age of patients. In patients aged $\leq 6$ months, genital virilization was found in 13 (30.2\%) cases. In patients aged >6months, genital virilization was found in $26(53.1 \%)$ cases. The difference was significant ( $\mathrm{p}$-value $<0.05$ ).

There were 49 (53.26\%) male while $43(46.74 \%)$ female infants. Data was stratified for gender of patients. In male patients, salt depletion was found in 37 (75.5\%) cases. In 
female patients, salt depletion was found in $26(60.5 \%)$ cases. The difference was insignificant ( $\mathrm{p}$-value $>0.05$ ). Data was stratified for gender of patients. In male patients, genital virilization was found in 17 (34.7\%) cases. In female patients, genital virilization was found in $22(51.2 \%)$ cases. The difference was insignificant (pvalue $>0.05$ ).

The mean weight of patients was $5.59 \pm 1.44 \mathrm{~kg}$. Data was stratified for weight of patients. In patients weighed 3.0$5.5 \mathrm{~kg}$, salt depletion was found in $30(71.4 \%)$ cases. In patients weighed $5.6-8.0 \mathrm{~kg}$, salt depletion was found in $33(66.0 \%)$ cases. The difference was insignificant (pvalue $>0.05$ ). Data was stratified for weight of patients. In patients weighed $3.0-5.5 \mathrm{~kg}$, genital virilization was found in $15(35.7 \%)$ cases. In patients weighed $5.6-8.0 \mathrm{~kg}$, genital virilization was found in $24(48.0 \%)$ cases. The difference was insignificant ( $\mathrm{p}$-value $>0.05$ ).

There were $21(22.83 \%)$ cases of consanguineous marriage while $71(77.17 \%)$ were other than cousin marriage. Data was stratified for consanguineous marriage. In patients with consanguineous marriage, salt depletion was found in $11(52.4 \%)$ cases. In patients without consanguineous marriage, salt depletion was found in $52(73.2 \%)$ cases. The difference was insignificant ( $\mathrm{p}$-value $>0.05$ ). Data was stratified for consanguineous marriage. In patients with consanguineous marriage, genital virilization was found in $8(38.1 \%)$ cases. In patients without consanguineous marriage, genital virilization was found in $31(43.7 \%)$ cases. The difference was insignificant ( $\mathrm{p}$-value $>0.05$ ).

\section{CONCLUSION}

Thus the frequency of patterns (salt depletion and genital virilization) of congenital adrenal hyperplasia are high in local population. Now the high prevalence has been proved. Now we will implement these results in local population and screen the patients in congenital adrenal hyperplasia patients to avert complications in future.

\section{ETHICAL APPROVAL}

The study was approved from Research Evaluation Unit, College of Physcian \& Surgeons of Pakistan, vide reference No. CPSP/REU/PED-2015-060-3416, dated December 19, 2017.

\section{REFERENCES}

1. Al-Jurayyan NA. The increased prevalence of congenital adrenal hyperplasia in Saudi Arabia: the role of consanguinity and multiple siblings involvement. European Journal of Research in Medical Sciences Vol 2015;3(1).

2. Khalid JM, Oerton JM, Dezateux C, Hindmarsh PC, Kelnar CJ, Knowles RL. Incidence and clinical features of congenital adrenal hyperplasia in Great Britain. Archives of disease in childhood 2012;97(2):101-106.
3. Khan AH, Aban M, Raza J, ul Haq N, Jabbar A, Moatter T. Ethnic disparity in 21-hydroxylase gene mutations identified in Pakistani congenital adrenal hyperplasia patients. BMC Endocrine Disorders [journal article] 2011;11(1):1-6.

4. Khan AH, Aban M, Raza J, Jabbar A, Moatter T. Classic virilizing congenital adrenal hyperplasia presenting late: case series from Pakistan. Journal of the Pakistan Medical Association 2009;59(9):643.

5. Speiser PW, Azziz R, Baskin LS, Ghizzoni L, Hensle TW, Merke DP, et al. Congenital adrenal hyperplasia due to steroid 21-hydroxylase deficiency: an Endocrine Society clinical practice guideline. The Journal of Clinical Endocrinology \& Metabolism 2010;95(9): 4133-4160.

6. Koh JW, Kim GH, Yoo HW, Yu J. Clinical features of congenital adrenal insufficiency including growth patterns and significance of ACTH stimulation test. Journal of Korean medical science 2013;28(11):1650-1656.

7. Al-Jurayyan N, Al-Herbish A, Abo BA, Al-Rabeeah A, Al-Samarrai A, Jawad A, et al. Congenital adrenal hyperplasia in a referral hospital in Saudi Arabia: Epidemiology, pattern and clinical presentation. Annals of Saudi medicine 1995;15(5):447-450.

8. Hassan MM, Ibrahim A, Abdel-Salam A, Huthail H. Growth in infants with congenital adrenal hyperplasia due to 21-hydroxylase deficiency: An analysis of the factors affecting height. Egyptian Pediatric Association Gazette 2013;61(2):57-62.

9. Knowles RL, Khalid JM, Oerton JM, Hindmarsh PC, Kelnar CJ, Dezateux C. Late clinical presentation of congenital adrenal hyperplasia in older children: findings from national paediatric surveillance. Archives of disease in childhood 2014;99(1):30-34.

10. Merke DP, Bornstein SR. Congenital adrenal hyperplasia. The Lancet 2005;365(9477):2125-2136.

11. Cutler Jr GB, Laue L. Congenital adrenal hyperplasia due to 21-hydroxylase deficiency. New England Journal of Medicine 1990;323(26):1806-1813.

12. Merke DP, Cutler GB. New approaches to the treatment of congenital adrenal hyperplasia. JAMA 1997;277(13):1073-1076.

\section{AUTHOR'S CONTRIBUTIONS}

HU: Manuscript writing

FMA: Data Collection

SH: Concept \& Design, Manuscript writing

NUAM: Data Collection, Literature Review

AA: Data analysis, Critical Review

SM: Supervision, Critical Review 